\title{
INSTITUTOS FEDERAIS DE EDUCAÇÃO: INDEPENDÊNCIA TECNOLÓGICA E DESENVOLVIMENTO SOCIAL
}

\section{FEDERAL INSTITUTE OF EDUCATION: TECHNOLOGY INDEPENDENCE AND SOCIAL DEVELOPMENT}

\author{
Vicente Zatti \\ Instituto Federal do Rio Grande do Sul - câmpus Canoas \\ E-mail: vicente.zatti@canoas.ifrs.edu.br
}

\section{Resumo}

O presente artigo analisa a proposta de educação profissional e tecnológica dos Institutos Federais de Educação em implantação no Brasil desde 2008. Fundados teoricamente na pedagogia de Paulo Freire, a partir da análise da legislação pertinente e de entrevistas focalizadas, buscamos elucidar as possibilidades de a proposta de educação profissional e tecnológica dos Institutos Federais de Educação promover a independência tecnológica e desenvolvimento social. Algumas características da proposta como foco em pesquisa aplicada, a verticalização, a capacitação técnica integrada à formação cultural mais ampla, a atuação em ensino, pesquisa e extensão, trazem possibilidades de um desenvolvimento tecnológico independente, enquanto a multiplicidade de foco permite o atendimento de demandas sociais como a necessidade de formação de professores nas áreas de ciências exatas e ciências da natureza e oferecimento de educação profissional e tecnológica a parcelas da população que historicamente foram excluídas do acesso à educação de qualidade.

Palavras-chave: educação profissional e tecnológica. Institutos Federais de Educação. independência tecnológica. desenvolvimento social.

\begin{abstract}
The present article analye the technological and professional education proposal of the Federal Institutes of education on deployment in Brazil since 2008. Founded theoretically in Paulo Freire pedagogy, from the analysis of the pertinent legislation and the targeted interviews, we search elucidate the possibilities of the technology and professional education proposal of the Federal Institutes of education to promote the technology independence and social development. Some characteristics of the proposal with focus in the applied research, the uprighting, the technical training intagrated to a more broad cultural formation, the performance in the education, research and extension, bring possibilities of one technological independent development, while the multiplicity of the focus allow the social demand attendance as the need formation of the teachers in the exact areas and the natural science and offering the professional and technological education to the population portions that historically were excluded of the access to a quality education.
\end{abstract}

Keywords: professional and technological education. Federal Institute of Education. technology undependence. social development. 


\section{INTRODUÇÃO}

O presente artigo é resultado de parte da pesquisa de doutorado realizada no Programa de Pósgraduação em Educação da Universidade Federal do Rio Grande do Sul, cuja tese foi defendida em 2012. Analisa o modelo de educação profissional e tecnológica em implantação no Brasil desde 2008 com a criação dos Institutos Federais de Educação. Adotamos a "entrevista focalizada" ${ }^{1}$ (MINAYO, 2009, p. 64) como método empregado na parte empírica da pesquisa pois, como o processo de implantação dos Institutos Federais de Educação ainda está ocorrendo, existem poucos dados e poucos resultados conclusivos; deste modo, é importante um método que possibilite a discussão entre os entrevistados para que possam ser levantadas questões, temas, problemas centrais desse processo. Foram constituídos dois grupos de discussão focalizada, cada um composto por três professores de um mesmo Câmpus. Os grupos foram constituídos nos Câmpus Canoas e Caxias do Sul do Instituto Federal do Rio Grande do Sul (IFRS) e as entrevistas ocorreram respectivamente em 12 de março de 2012 e 19 de março de 2012. A configuração dos grupos com professores do mesmo Câmpus teve como objetivo primar pela discussão, que é facilitada pelo fato de esses professores conviverem no exercício profissional. Segundo Minayo (2009, p.64), a entrevista focalizada utiliza entrevistados escolhidos de modo intencional com o objetivo de esclarecer um determinado problema. Os entrevistados assinaram Termo de Consentimento Livre e Esclarecido, no qual consta o número de CPF e assinatura dos mesmos. Em cumprimento aos termos de sigilo estabelecidos no Termo de Consentimento Livre e Esclarecido, ao longo do artigo as falas dos entrevistados aparecem desidentificadas. Quando citamos a fala de um professor especificamente a referência é feita através dos termos desidentificados Prof. 1, Prof. 2, Prof. 3, Prof. 4, Prof. 5, Prof. 6. Para a condução da discussão na entrevista foi utilizado um Roteiro para Entrevista Focalizada semiestruturado.

As categorias discutidas na entrevista surgiram a partir da discussão teórica fundada na pedagogia dialógica freireana e na teoria da ação comunicativa habermaseana e também na legislação que cria e orienta a implantação dos Institutos Federais de Educação. Quanto à legislação, tomamos como referência principal a Lei 11.892, de 29 de dezembro de 2008 que cria os Institutos Federais de Educação e o documento elaborado pelo MEC em 2010 denominado Instituto Federal de Educação, Ciência e Tecnologia: Um modelo em educação profissional e tecnológica. Concepção e

\footnotetext{
${ }^{1}$ Também conhecida como "grupo focal" ou "grupo de discussão focalizada".
} 
Diretrizes. A partir do tripé análise teórica, análise documental e entrevista focalizada, desenvolvemos abaixo algumas das categorias levantadas na pesquisa e que buscam discutir se as possibilidades de a proposta educacional dos Institutos Federais de Educação contribuir para a independência tecnológica e desenvolvimento social do Brasil.

\section{SUPERAÇÃO DA DEPENDÊNCIA CULTURAL}

Nas entrevistas focalizadas a questão da dependência tecnológica apareceu como relacionada à dependência cultural, como podemos perceber na fala do Prof. 6, "a formação crítica é fundamental pois a dependência tecnológica não é só uma questão técnica mas uma questão de mentalidade. A questão da dependência cultural é uma discussão que tem que passar por todo mundo, não só os alunos." Logo em seguida, acrescenta ele: “dependência tecnológica não está relacionada apenas ao desenvolvimento técnico, mas também formação intelectual mais ampla, é também uma questão de mentalidade". Como exemplo citou a resistência que em geral ocorre quanto ao uso do Software Livre. Segundo ele, há Softwares Livres tão eficientes quanto aqueles produzidos pelas grandes multinacionais da informática, mas as pessoas continuam utilizando os últimos. Isso ocorre porque estão dependentes da tecnologia por questões que estão ligadas à forma de pensar e não falta de outras opções tecnológicas adequadas. Portanto, superação da dependência tecnológica não envolve apenas desenvolvimento tecnológico, envolve superação de uma mentalidade ideologicamente constituída. A dependência cultural serve como forma de perpetuar a dependência tecnológica de um povo em relação a outro, daí a importância de uma educação que do ponto de vista cultural possibilite o pensar crítico. A relação entre cultura e tecnologia também aparece nas diretrizes do MEC para os Institutos Federais de Educação:

Os Institutos Federais de Educação, Ciência e Tecnologia [...] propõem uma educação em que o domínio intelectual da tecnologia, a partir da cultura, firmase. Isto significa dizer que as propostas de formação estariam contemplando os fundamentos, princípios científicos e linguagens das diversas tecnologias que caracterizam o processo de trabalho contemporâneo, consideradas historicamente (MEC, 2010, p. 33). 
O documento orienta que a educação profissional e tecnológica dos Institutos Federais de Educação não se restrinja apenas à reprodução da tecnologia, mas se volte ao domínio intelectual da tecnologia que deve se dar a partir da cultura. Essa é uma questão basilar para essa proposta educacional, considerando que nossa dependência tecnológica histórica está acompanhada de dependência cultural. Sobre isso, afirma Freire (1981, p. 35), "Assim também a imitação servil de outras culturas produz uma sociedade alienada ou sociedade-objeto. Quanto mais alguém quer ser outro, tanto menos é ele mesmo." Em Freire $(1983$, p. 178) essa questão é vista como invasão cultural, o dominado passa a compreender o mundo a partir da ótica do dominador. "A invasão cultural, que serve à conquista e à manutenção da opressão, implica sempre na visão focal da realidade, na percepção desta como estática, na superposição de uma visão do mundo na outra." (FREIRE, 1983, p. 188). Portanto, ao falarmos em superação da dependência tecnológica precisamos falar sim em pesquisa alicerçada no domínio intelectual dos conhecimentos para desenvolvermos tecnologias próprias. Mas a primeira etapa para a superação da dependência tecnológica é rompermos com a dependência cultural. Isso implica em produzir um universo de sentido linguístico-cultural não dependente: “Na verdade, nenhum colonizado, como indivíduo ou como nação, sela sua libertação, conquista ou reconquista sua identidade cultural sem assumir sua linguagem, seu discurso e por eles ser assumido." (FREIRE, 1999, p. 178). A superação da histórica dependência tecnológica brasileira não ocorrerá se o caminho escolhido for exclusivamente o desenvolvimento técnico, pois a dependência tecnológica supõe e é mantida pela dependência cultural. Desse modo, um modelo de desenvolvimento alicerçado exclusivamente num projeto de inovação técnico-tecnológico é estéril se não estiver integrado a uma formação cultural mais ampla dos educandos. 


\section{O PAPEL DA PESQUISA APLICADA: DESENVOLVIMENTO LOCAL E REGIONAL}

Quanto à pesquisa, a Lei $11.892 / 2008$ no seu Artigo 70, inciso III, define como um dos objetivos dos Institutos Federais de Educação a realização de pesquisa aplicada ${ }^{2}$. Os professores entrevistados veem na pesquisa aplicada a possibilidade de superar a dependência tecnológica histórica do Brasil, e também pensam que isto está diretamente relacionado à possibilidade de emancipação. Tal perspectiva emancipatória caracteriza, pois, que a pesquisa aplicada deve estimular o "desenvolvimento de soluções técnicas e tecnológicas, estendendo seus benefícios à comunidade." (BRASIL, 2008, Arto 7, Inciso III). A pesquisa aplicada é definida com esse compromisso em auxiliar a comunidade a resolver os seus problemas. "É nesse espírito que se entende o termo pesquisa aplicada: a capacidade de aplicar seus resultados para melhoria das condições de vida em uma localidade." (JURACY, 2009, p. 43). Por isso a Lei 11.892/2008 no Art 60, inciso IV, estabelece que a oferta de cursos a serem oferecidos busque consolidar e fortalecer os arranjos produtivos, sociais e culturais locais, "identificados com base no mapeamento das potencialidades de desenvolvimento socioeconômico e cultural no âmbito de atuação do Instituto Federal." Desse modo, a pesquisa nos Institutos Federais deve estar voltada para desenvolver tecnologias que dialogam com o mundo (comunidade) no qual a instituição está inserida. Portanto, a pesquisa possui um compromisso com a transformação desses espaços.

Os Institutos Federais constituem um espaço fundamental na construção dos caminhos com vista ao desenvolvimento local e regional. Para tanto, devem ir além da compreensão da educação profissional e tecnológica como mera instrumentalizadora de pessoas para o trabalho determinado por um mercado que impõe objetivos. É imprescindível situá-los como potencializadores de uma educação que possibilita ao indivíduo o desenvolvimento de sua capacidade de gerar conhecimentos a partir de uma prática interativa com a realidade. Ao mergulharem sua própria realidade, esses sujeitos devem extrair e problematizar o conhecimento, investigar o desconhecido para poder compreendê-lo e influenciar a trajetória dos destinos de seu lócus de forma a tornar-se

\footnotetext{
${ }^{2}$ Embora os entrevistados tenham reconhecido a pesquisa aplicada como prioridade nos Institutos Federais de Educação, ponderaram que não deve ser descartada a pesquisa básica. Isso em função da diversidade da formação dos professores, talvez nem todos tenham possibilidade de realizar pesquisa aplicada. Nesse sentido, merece destaque a fala do entrevistado Prof. 4: "Quanto à diferença entre pesquisa básica e aplicada, isso é irrelevante, depende da área, do perfil do pesquisador e dos objetivos da pesquisa".
} 
credenciados a ter uma presença substitutiva a favor do desenvolvimento local e regional (MEC, 2010, p. 22).

Para possibilitar o desenvolvimento local e regional a escolha dos eixos tecnológicos e dos cursos deve levar em conta os arranjos produtivos locais. Segundo o entrevistado Prof. 4, a definição desses eixos tecnológicos "deve passar por uma articulação política com os sindicatos". A articulação com a comunidade e os sindicatos possibilita um reconhecimento mais exato das potencialidades dos arranjos produtivos locais. O desafio da pesquisa nos Institutos Federais de Educação é ir além da descoberta científica, "[...] os novos conhecimentos produzidos pelas pesquisas deverão estar colocados a favor dos processos locais e regionais numa perspectiva de reconhecimento e valorização dos mesmos no plano nacional e global" (PACHECO, 2010, p. 25). Cabe à pesquisa aplicada possibilitar a compreensão do mundo para que esse desvelamento possibilite tanto a assunção cultural quanto a transformação concreta da realidade:

Compreensão do mundo que, condicionada pela realidade concreta que em parte a explica, pode começar a mudar através da mudança do concreto. Mais ainda, compreensão do mundo que pode começar a mudar no momento mesmo em que o desvelamento da realidade concreta vai deixando expostas as razões de ser da própria compreensão tida até então (FREIRE, 1999, p. 27 - 28).

Mas, segundo os entrevistados, quanto à pesquisa aplicada, os Câmpus dos Institutos Federais de Educação estão muito distantes de alcançar os objetivos estabelecidos e realizar suas possibilidades, tanto em quantidade quanto em qualidade. Por exemplo, o Prof. 1 afirmou "o nosso Instituto vejo distante disso por questões de organização e planejamento". Um dos fatores para que a pesquisa não esteja efetivando seu potencial, é a tímida e quase inexistente implantação de Programas de Pós-graduação stricto sensu. Quanto às dificuldades de implantação dos PPGs, que certamente alavancariam as pesquisas aplicadas, listamos algumas principais: 1) Os Institutos Federais de Educação são instituições jovens, muitos Câmpus estão em implantação ${ }^{3}$, portanto, sem toda a estrutura física necessária instalada, como laboratórios, por exemplo. Segundo o entrevistado Prof. 4 "Ainda não estamos atingindo produção tecnológica pois não há condições para tal. A sede do Câmpus ainda não foi entregue e não há laboratórios". 2) O corpo 
docente é bastante heterogêneo e está em fase de constituição. Tal heterogeneidade se caracteriza pela formação, alguns ingressam sem formação stricto sensu, outros com mestrado e outros com doutorado. Também há heterogeneidade com relação à experiência em pesquisa aplicada, alguns profissionais antes de ingressar nos Institutos Federais de Educação, eram estudantes de Pósgraduação, outros professores de educação básica, outros professores universitários, etc. Tais elementos refletem no que caracterizou o Prof. 1, "Como vamos montar um mestrado se estamos ainda montando os grupos de pesquisa? Se ainda não temos publicações?" 3) O foco amplo de atuação dos Institutos Federais de Educação pode dispersar a atuação e prejudicar o desenvolvimento da pesquisa. Essa multiplicidade de foco traz potencialidades, mas também traz o risco de a pesquisa não tornar-se uma questão central nos Institutos Federais de Educação.

\section{INDISSOCIABILIDADE DE ENSINO, PESQUISA E EXTENSÃO}

Segundo o Ministério da Educação (2010, p. 6), os processos de formação nos Institutos Federais de Educação devem estar orientados nas premissas da integração e articulação entre ciência, tecnologia, cultura, conhecimentos específicos e desenvolvimento da capacidade de investigação científica como dimensões essenciais à manutenção da autonomia e dos saberes necessários ao permanente exercício de laboralidade, que se traduzem nas ações de ensino, pesquisa e extensão. O ensino serve de suporte para a pesquisa, que por sua vez potencializa o ensino. Ambos precisam estar conectados com as comunidades locais em ações de extensão para que contribuam no desenvolvimento econômico e cultural locais. Desse modo, estarão cumprindo objetivos estratégicos que vão além da qualificação de mão de obra: “[...] fator estratégico não apenas na compreensão da necessidade do desenvolvimento nacional, mas também como um fator para fortalecer o processo de inserção cidadã para milhões de brasileiros." (MEC, 2010, p. 18). O potencial de superação da dependência tecnológica e desenvolvimento que a pesquisa possui, é ampliado na medida em que está articulada com o ensino e a extensão.

\footnotetext{
${ }^{3}$ Em função do atraso nas obras e outras questões que não cabe aqui investigar, há muitos casos em que a construção da estrutura física não foi finalizada ou foi entregue parcialmente.
} 
O desafio colocado para os Institutos Federais no campo da pesquisa é, pois, ir além da descoberta científica. Em seu compromisso com a humanidade, a pesquisa, que deve estar presente em todo o trajeto de formação do trabalhador, deve representar a conjugação do saber e de mudar e se construir, na indissociabilidade de pesquisa, ensino e extensão. (MEC, 2010, p. 35).

Os entrevistados consideraram a articulação entre pesquisa, ensino e extensão fundamental para possibilitar a emancipação, já que dessa forma os três elementos se potencializam. Essa potencialização está suposta na seguinte frase do Prof. 6: "Tinha a visão de que os Institutos Federais de Educação formavam apenas mão de obra, mas mudei de visão após trabalhar aqui. A discussão que é feita em sala de aula, além das atividades de pesquisa e extensão, dão sim uma formação crítica." O mesmo entrevistado afirmou que nas universidades federais a extensão parece possuir um destaque menor do que a pesquisa e o ensino, já esse problema não ocorre nos Institutos Federais de Educação: "a universidade federal prioriza a pesquisa, a extensão parece ter menor importância, já nos institutos federais a extensão tem maior relevância". A importância, a que se refere o entrevistado, que é dada à extensão está relacionada ao modelo de educação dos Institutos Federais de Educação, uma educação comprometida com o desenvolvimento local e regional e, que por isso, precisa manter constantemente o diálogo com a realidade na qual está inserida.

Aos Institutos Federais [...] cabe provocar a atitude de curiosidade frente ao mundo e dialogar com este mundo numa atitude própria de pesquisa. Na relação com a pesquisa, o ato de pesquisar, nos Institutos Federais, deve vir ancorado em dois princípios: o princípio científico, que se consolida na construção da ciência, e o princípio educativo, que diz respeito à atitude de questionamento diante da realidade. (MEC, 2010, p. 35).

Tal concepção está de acordo com a proposta de educação dialógica de Paulo Freire: “Ensinar é assim a forma que toma o ato do conhecimento que o professor necessariamente faz na busca de saber o que ensina para provocar nos alunos seu ato de conhecimento também. Por isso, ensinar é um ato criador, um ato crítico e não mecânico". (FREIRE, 1999, p. 81). A relação dialógica não anula a possibilidade do ato de ensinar, pois ensinar e aprender estão interligados. "Por isso mesmo a 
formação técnico-científica de que urgentemente precisamos é muito mais do que puro treinamento ou adestramento para o uso de procedimentos tecnológicos." (FREIRE, 2000, p.102). Em uma educação dialógica o ensino e a pesquisa se complementam na tematização e problematização do mundo. Por isso Freire $(2007$, p. 27$)$ refere-se à pura memorização como um obstáculo para a construção de uma educação crítica, pois desse modo, os conhecimentos parecem inertes, desconexos com a realidade e sem uma história de produção. A simples memorização nega algo que é constitutivo do ensino, a pesquisa.

Não há ensino sem pesquisa e pesquisa sem ensino. Esses que-fazeres se encontram um no corpo do outro. Enquanto ensino continuo buscando, reprocurando. Ensino porque busco, porque indaguei, porque indago e me indago. Pesquiso para constatar, constatando, intervenho, intervindo educo e me educo. Pesquiso para conhecer o que ainda não conheço e comunicar ou anunciar a novidade. (FREIRE, 2007, p. 29).

Ensinar não é transferir conhecimento, mas criar as possibilidades para sua própria produção e a sua construção. (cf. FREIRE, 2007, p. 47). O ensino que opta pelo contrário, transferir conhecimentos pura e simplesmente, nega a historicidade do conhecimento e reduz a educação a treinamento. "A necessária formação técnico-científica dos educandos por que se bate a pedagogia crítica não tem nada que ver com a estreiteza tecnicista e cientificista que caracteriza o mero treinamento." (FREIRE, 2000, p. 44). Ao mantermos práticas que se reduzem a treinamento, estaremos perpetuando situações estabelecidas de dependência tecnológica e alienação cultural.

Portanto, a indissociabilidade entre ensino, pesquisa e extensão é elemento fundamental para a superação de uma educação que se reduz a treinamento, e para a configuração de uma educação emancipatória que problematiza o mundo de forma a possibilitar ao mesmo tempo inovação tecnológica e a apreensão crítica da realidade. Mas, segundo os entrevistados Prof. 4 e Prof. 5, "há dificuldades em transformar uma instituição viciada", pois, mesmo havendo nos Institutos Federais de Educação uma articulação entre ensino, pesquisa e extensão, na organização institucional a "prioridade é o ensino". 


\section{DADOS DA PESQUISA}

Sobre o foco dos Institutos Federais de Educação, o Ministério da Educação estabelece:

O foco dos Institutos Federais será a justiça social, a equidade, a competitividade econômica e a geração de novas tecnologias. Responderão, de forma ágil e eficaz às demandas crescentes por formação profissional, por difusão de conhecimentos científicos e tecnológicos e de suporte aos arranjos produtivos locais. (MEC, 2010, p. 3).

Como podemos ler acima, o foco de atuação é múltiplo. Essa questão da multiplicidade de foco apareceu nas falas dos entrevistados como uma questão controversa. De um lado, a diversidade de foco é um potencial sem igual para o avanço tecnológico pois possibilita trocas de experiências entre diferentes níveis de ensino, o que qualifica o espaço educacional. Também, tal multiplicidade abre as portas dos Institutos Federais de Educação para uma parcela da população que historicamente não tinha acesso a essas instituições, como afirma o Prof. 3 "pode auxiliar no resgate social de públicos específicos". Exemplo disso são os cursos de Formação Inicial e Continuada (FIC) e de formação de jovens e adultos na modalidade PROEJA. Por outro lado é preciso atenção para que essa amplitude de foco não disperse as ações e dificulte a atuação na pós-graduação e na inovação tecnológica. Talvez por isso, segundo o Prof. 3, "há certa resistência nos Câmpus em instalar tudo". Como afirma Juracy (2009, p. 23), "Essa diversidade não pode ser confundida com dispersão. Não se trata de um conjunto aleatório de cursos." O principal mecanismo para evitar tal dispersão de foco é a verticalização, o que implica em implantação de cursos restritos a eixos de conhecimento/tecnológicos específicos. A multiplicidade de foco deve estabelecer sua unidade nos eixos tecnológicos.

A verticalização nos Institutos Federais de Educação é estabelecida legalmente "da educação básica à educação profissional e superior" (BRASIL, 2008, Art 6 Inciso III). Considerando que a educação superior engloba cursos superiores de tecnologia, cursos de licenciatura, cursos de bacharelado e engenharia, pós-graduação lato sensu, stricto sensu de mestrado e doutorado (cf. BRASIL, 2008, Art 7ํ Inciso VI), os Institutos Federais de Educação têm a possibilidade de atuação com pesquisa do ensino médio ao doutorado, falando de modo mais amplo, a verticalização 
permite pensar um currículo que conecta ensino, pesquisa e extensão, atravessando vários níveis de ensino.

Para os entrevistados, a verticalização está diretamente relacionada com a superação da dependência tecnológica. A verticalização possibilita pensar um itinerário formativo que atravessa vários níveis, permite que se desenvolvam pesquisas que envolvam discentes e articulem os cursos do ensino médio ao doutorado. Na fala do entrevistado Prof. 4, "num mesmo laboratório teremos pesquisadores de diferentes níveis, do ensino médio ao doutorado. Esse sujeito que está trabalhando com pesquisa desde o ensino médio vai ter uma capacidade muito maior de produzir quando estiver no pós-graduação." Essa especificidade da pesquisa aplicada nos Institutos Federais de Educação constitui um potencial estratégico para inovação tecnológica. Portanto, a efetivação da verticalização é fundamental para que tais instituições possam contribuir com a superação da dependência tecnológica histórica de nosso país. Mas, segundo os entrevistados, para que tal verticalização se potencialize ela deve ocorrer em torno de eixos tecnológicos. A organização dos cursos em torno dos eixos tecnológicos possibilita o uso mais eficiente de recursos físicos (como laboratórios), dos recursos humanos e, principalmente, possibilita a criação de um universo interativo qualificado no qual um grande número de professores e discentes poderão interagir e cooperar em torno de problemas comuns.

\section{INSTITUTOS FEDERAIS DE EDUCAÇÃO COMO POLÍTICA PÚBLICA}

Segundo o Ministério da Educação (MEC, 2010, p. 7), com a criação dos Institutos Federais, afirmase a educação profissional e tecnológica como uma política pública, e a política pública assenta-se em itens obrigatórios como estar comprometida com o todo social. Esse é o discurso central dos documentos do MEC e da legislação que instituiu os Institutos Federais de Educação, os quais estabelecem a perspectiva de uma educação que pretende não apenas capacitar mão de obra para satisfazer a demanda gerada pelo crescimento econômico nacional, mas estão preocupados em dialogar com a sociedade como um todo e, principalmente, contribuir no resgate social dos grupos que historicamente foram excluídos.

O papel que está previsto para os Institutos Federais é garantir a perenidade das ações que visem a incorporar, antes de tudo, setores sociais que historicamente 
foram alijados dos processos de desenvolvimento e modernização do Brasil, o que legitima e justifica a importância da sua natureza pública e afirma uma educação profissional e tecnológica como instrumento realmente vigoroso na construção e resgate da cidadania e da transformação social. (MEC, 2010, p.21).

Desse modo, os Institutos Federais de Educação realizam seu "[...] verdadeiro papel social, contribuindo para uma sociedade menos desigual, mais autônoma e solidária." (MEC, 2010, p. 7). O mesmo documento atribui a essas instituições a qualidade de "incubadora de políticas sociais" (MEC, 2010, p. 19) e, em outra passagem, “observatório de políticas públicas" (MEC, 2010, p. 19) e, ainda, "rede social" (MEC, 2010, p. 24). Isso lega para os Institutos Federais de Educação, a necessidade de interagirem com a sociedade em dimensões múltiplas, não apenas no que se refere ao desenvolvimento da técnica e da ciência: “[...] verdadeira incubadora de políticas sociais, uma vez que constroem uma rede de saberes que entrelaça cultura, trabalho, ciência e tecnologia em favor da sociedade." (MEC, 2010, p. 19). Portanto, a prioridade de estabelecer-se como educação fomentadora de inovação tecnológica com vistas à superação de nossa dependência tecnológica histórica, está acompanhada de um compromisso social e político:

Trata-se de um projeto progressista que entende a educação como compromisso de transformação e de enriquecimento de conhecimentos objetivos capazes de modificar a vida social e de atribuir-Ihe maior sentido e alcance ao conjunto da experiência humana, proposta incompatível com uma visão conservadora de sociedade. Trata-se, portanto, de uma estratégia de ação política e de transformação social (MEC, 2010, p. 18).

Os entrevistados consideraram que o estabelecimento dessa perspectiva que insere 0 compromisso social como elemento central nos Institutos Federais de Educação é um importante avanço para a educação profissional e tecnológica da rede federal de ensino pois, antes da criação desse novo modelo, conforme Prof. 1, "o social não aparecia", ou seja, a educação ficava mais restrita ao desenvolvimento de competências técnico-científicas. Acrescenta o entrevistado "há avanços porque antes, nos CEFETs, o social não era tematizado". Embora alguns entrevistados tenham dado maior ênfase a esse aspecto, de acordo com suas convicções sócio-políticas pessoais, todos concordaram que uma educação emancipatória envolve também a transformação social. E, como afirma o Prof. 6, "dentro de um contexto maior há a primazia do social". 
Corroborando com essa ideia, o Prof. 4 afirmou que nos Institutos Federais de Educação "o contato com a comunidade externa é mais presente, mais constante e mais valorizado" do que era nas instituições federais de educação profissional e tecnológica anteriores.

Mas, paradoxalmente ao acima descrito, foi unânime a consideração de que o discurso estabelece a primazia do social, mas isso não representa exatamente o que ocorre na prática. A proposta está centrada no social, mas na prática a primazia é atender o desenvolvimento econômico, "o social é acessório" (Prof. 3). Nesse sentido, afirma o Prof. 4, "Na prática ocorre a primazia do desenvolvimento econômico, se der se atende o social, e não primazia do desenvolvimento social." Mesmo assim eles afirmaram que esse modelo de desenvolvimento econômico não está desapegado do desenvolvimento social e "o problema é quando o desenvolvimento econômico está desapegado do desenvolvimento social" (Pro. 6). Essas afirmações, que revelam certo paradoxo sobre a compreensão da questão, demonstram que há uma desconfiança com possíveis interesses ocultos na proposta de educação profissional e tecnológica dos Institutos Federais de Educação. Ou seja, o discurso legal é da primazia do social, da formação que não objetiva apenas capacitar mão de obra e, há avanços concretos nesse sentido como já demonstramos, mas há a suspeita levantada pelos entrevistados que no bojo de tal proposta podem haver interesses sistêmicos que ficam camuflados.

\section{A PERSPECTIVA E INCLUSÃO SOCIAL}

O Ministério da Educação coloca como papel dos Institutos Federais de Educação "ações que visem a incorporar, antes de tudo, setores sociais que historicamente foram alijados dos processos de desenvolvimento e modernização do Brasil." (MEC, 2010, p. 21). Ou seja, uma de suas missões é o resgate de setores sociais que ao longo da história do país foram excluídos. Tal aspecto é reforçado em outra passagem do documento: "A realidade que se vislumbra com esses Institutos Federais é que eles constituam um marco nas políticas para a educação no Brasil, pois revelam uma dimensão da educação profissional alinhada com as políticas de inclusão e com um projeto de nação" (MEC, 2010, p. 39). Desse modo, a partir das diretrizes estabelecidas pelo MEC, a perspectiva da inclusão social deve acompanhar o planejamento e as ações realizadas nos Institutos Federais de Educação. 
Nas entrevistas, um dos elementos levantados é que o compromisso social que é dado aos Institutos Federais de Educação nos remete a questão de com quem se está disposto a trabalhar, ou seja, é preciso atender aqueles que historicamente foram desfavorecidos, é o que afirma o entrevistado Prof. 3 "A primazia do social envolve com quem se está disposto a trabalhar. É preciso trabalhar com as pessoas desfavorecidas." Nesse sentido também aponta o pensamento do educador Paulo Freire. Tal opção política fica clara na epígrafe do seu livro Pedagogia da Oprimido: "Aos esfarrapados do mundo e aos que neles se descobrem e, assim descobrindo-se, com eles sofrem, mas, sobretudo, com eles lutam" (FREIRE, 1983, p. 17). Acrescenta o Prof. 3, "Se falamos em primazia do social é preciso pensar a questão do acesso. No nosso processo atual de acesso há o privilégio, pois os que conseguem as melhores notas no processo seletivo não são os mais pobres, o que é uma contradição." Ou seja, o entrevistado apontou a existência de uma contradição entre a legislação que aponta a primazia do social e o processo seletivo com prova por mérito como forma de acesso às vagas nos cursos dos Institutos Federais de Educação. $O$ ingresso por meio de processo seletivo promove a elitização do perfil dos alunos, tendo em vista que em geral são selecionados aqueles que tiveram acesso às melhores condições e melhores escolas. Isso porque, segundo Prof. 3, "parte-se do pressuposto de que a educação é para a elite, pois se trabalha com um nível alto de exigência que é desconexo da realidade". 0 entrevistado Prof. 2 colocou que a questão do acesso é difícil e controversa, pois não há vagas para todos que procuram os Institutos Federais de Educação e se faz necessária alguma forma de seleção. Considerando que um dos objetivos é trabalhar com inovação tecnológica, selecionar alunos mais preparados é um fator importante. Mas dessa forma, como fica o resgate das populações que historicamente foram excluídas? No outro grupo o entrevistado Prof. 4 citou o princípio da equidade para justificar a necessidade de cotas, o que possibilitaria adotar critérios desiguais para quem possui condições desiguais. "As cotas são uma forma de garantir a equidade, é muito injusto apenas fazer uma prova, a política de cotas garante que a diversidade seja garantida." Mas tal ponto permaneceu como impasse, os grupos não chegaram a consenso, o que reforça o complexo elemento de escolha política que está por trás de tal questão.

Exemplo citado nos grupos entrevistados de realização da perspectiva de inclusão social foram os cursos de educação profissional para jovens e adultos na modalidade PROEJA. A Lei 11.892/2008, no Artigo 7ำ, Inciso I, quando põe a educação profissional técnica de nível médio como um dos objetivos dos Institutos Federais de Educação, cita a oferta "para o público da educação de jovens 
e adultos". Os Câmpus têm implantado tais cursos e isso é fundamental para o resgate social e inclusão de trabalhadores que não tiveram a oportunidade de realizar o ensino médio quando adolescentes. $O$ entrevistado Prof. 5 destacou que além do oferecimento de tais cursos, o que já ocorre, é preciso que eles estejam inseridos no princípio da verticalização, para que após o término do curso na modalidade PROEJA, os trabalhadores tenham opções de na instituição continuar seus estudos.

\section{FORMAÇÃO INICIAL E CONTINUADA}

Lei 11.892/2008, no Artigo 7으, Inciso II coloca como um dos objetivos dos Institutos Federais de Educação "ministrar cursos de formação inicial e continuada de trabalhadores, objetivando a capacitação, o aperfeiçoamento, a especialização e a atualização de profissionais, em todos os níveis de escolaridade, nas áreas da educação profissional e tecnológica". A definição desse objetivo vem ao encontro do papel que essas instituições possuem com a extensão. Os entrevistados dos dois grupos foram unânimes em reconhecer que os cursos de Formação Inicial e Continuada (FIC) podem possibilitar a oportunidade para os trabalhadores terem uma qualificação em curto prazo e desse modo inserirem-se no mercado de trabalho rapidamente, o que para pessoas pobres é uma questão crucial de sobrevivência. Aqui nós percebemos a importância social da extensão e, principalmente, a importância da articulação ensino/pesquisa com as demandas de extensão que possibilitam o resgate social.

A questão dos cursos FIC mostrou-se um pouco polêmica e controversa, isso porque na ocasião das entrevistas o país estava vivendo a implantação do PRONATEC ${ }^{4}$ (Programa Nacional de Acesso ao Ensino Técnico e Emprego), que está criando uma grande quantidade desses cursos. Assim sendo, a discussão sobre os cursos de Formação Inicial e Continuada esteve permeada pela questão do PRONATEC. O ponto controverso dos cursos FIC é que eles, se desenvolvidos isoladamente, não fornecem formação nem integral e nem possibilitam a apreensão dos fundamentos científicos, são, portanto, insuficientes para emancipar ${ }^{5}$. Esse aspecto foi fortemente

\footnotetext{
${ }^{4}$ O Programa Nacional de Acesso ao Ensino Técnico e Emprego (PRONATEC) foi criado em 26 de outubro de 2011 pela Lei № 12.513/2011. Prevê duas modalidades de cursos, de Formação Inicial e Continuada (FIC) e Técnicos. Fonte: pronatec.mec.gov.br/pronatec.html, acesso em 05/05/12.

${ }^{5}$ Essa crítica foi feita pelos entrevistados ao PRONATEC como um todo. Um dos importantes avanços dos Institutos Federais de Educação no oferecimento de uma educação com vistas à emancipação é o currículo integrado. $O$
} 
enfatizado por todos entrevistados. Além disso, há a questão da estrutura dos Institutos Federais de Educação e a formação acadêmica de seus professores, que são mais adequados para a realização de cursos que trabalhem ao mesmo tempo com a técnica e com a ciência, e não apenas a uma capacitação técnica pontual.

\section{A FORMAÇÃO DE PROFESSORES}

A Lei 11.892/2008 no Art 70 Inciso VI, ao referir-se às modalidades de ensino superior estabelece "cursos de licenciatura, bem como programas especiais de formação pedagógica, com vistas na formação de professores para a educação básica, sobretudo nas áreas de ciências e matemática, e para a educação profissional." A mesma lei, no Artigo 8a, estabelece que no mínimo $20 \%$ das vagas dos Institutos Federais de Educação devem ser de cursos de licenciaturas. Para os entrevistados, colocar cursos de licenciaturas nos Institutos Federais de Educação é mais uma política pública, essa com foco na solução de um problema que é a falta de professores e deficiências na qualificação de professores que atuam na educação básica.

De acordo com as diretrizes do MEC para os Institutos Federais de Educação, na oferta dessas licenciaturas ${ }^{6}$ "não se poderia prescindir do traçado de um paradigma para a formação pedagógica que ultrapasse as propostas de licenciaturas até então ofertadas" (MEC, 2010, p. 30). A proposta é que tais cursos de licenciatura promovam a "superação de dicotomias entre ciência/tecnologia, entre teoria/prática; a superação da visão compartimentada de saberes" (Idem) e sejam capazes de "fortalecer o sentimento crítico a respeito do lugar e da história que se constrói e de que projeto de sociedade se pretende" (Idem) e ainda "a possibilidade de repensar a educação superior de forma consciente, na perspectiva de superação de distorções históricas" (Idem). O discurso oficial sobre a implantação das licenciaturas nos Institutos Federais de Educação parte, por um lado, da crítica das experiências de licenciaturas nas universidades e, por outro, da carência

PRONATEC vem na contramão dessa direção, pois tanto os cursos FIC quanto os cursos técnicos desse programa não abarcam o currículo integrado.

${ }^{6}$ Sobre esse aspecto, o ponto de vista de Delphino é divergente da proposta do Ministério da Educação: "Somente quando finalmente conseguir atrelar-se a centros criadores de ciência e tecnologia, que proporcionem uma visão crítica do conjunto do sistema e do processo produtivo, será livre dos instrumentos de dominação que o cercam e fará com que a escola se transforme em favor de desenvolvimento humano e social. Estes centros de ciência e tecnologia podem ser IFs, no Brasil, se estes cessarem a disputa por espaço com as universidades, deixando de lado sua ambição por licenciaturas e pós-graduação e realmente assumirem esta missão". (DELPHINO, 2010, p. 205) 
de professores da educação básica especialmente nas áreas de ciências e matemática, mas, não define claramente mecanismos e condições para que tais licenciaturas inovadoras se estabeleçam.

A proposta de os Institutos Federais de Educação atuarem com formação de professores é uma experiência completamente nova e bastante nebulosa na medida em que é difícil ter clareza de seus possíveis resultados. Os entrevistados reconhecem essa como mais uma política pública que o governo federal legou para os Institutos Federais de Educação, mas não arriscaram um posicionamento muito claro sobre o assunto. Ou seja, não há referenciais empíricos consolidados para uma avaliação mais precisa desse aspecto. Na medida em que visa melhorar a qualidade da educação básica brasileira, enquanto proposta é importante para a emancipação. No entanto, as condições para que essas licenciaturas se efetivem tal e qual propostas não estão claramente estabelecidas. Desse modo, avaliações mais precisas sobre a realização de suas finalidades devem ser feitas em pesquisas futuras quando houver evidências empíricas para tal.

\section{A TRANSFORMAÇÃO CONCRETA DA REALIDADE}

Estamos demonstrando que os Institutos Federais de Educação são criados com o compromisso social de interagir com a sociedade em dimensões múltiplas (cultura, trabalho, ciência e tecnologia). Representam uma política pública comprometida com a transformação da realidade no sentido de superar a exclusão social e gerar desenvolvimento econômico. Para o entrevistado Prof. 3, esse é uma das perspectivas fundamentais desse modelo de educação, de tal modo que a formação intelectual deve levar ao pensar autonomamente e isso implica em transformar a realidade: "acredito na autonomia na perspectiva de que o sujeito consegue através da educação transformar a realidade na qual ele está inserido" (Prof. 3). Tal concepção educativa alia-se à proposta educacional de Paulo Freire: "Práxis que, sendo reflexão e ação verdadeiramente transformadora da realidade, é fonte de conhecimento reflexivo e criação" (FREIRE, 1983, p. 108). A educação não se restringe ao ato de conhecer, conhecer implica também em transformar a realidade. Freire utiliza o conceito de 'quefazer', o que implica em poder conhecer e transformar o mundo com seu trabalho: "Mas se os homens são seres do quefazer é exatamente porque seu fazer é ação e reflexão. É práxis. É transformação do mundo." (FREIRE, 1983, p. 145). Ou seja, a concepção epistemológica de Freire estabelece uma relação direta entre conhecer e transformar o mundo. 
Mulheres e homens, somos os únicos seres que, social e historicamente, nos tornamos capazes de aprender. Por isso, somos os únicos em quem aprender é uma aventura criadora, algo, por isso mesmo, muito mais rico do que meramente repetir a lição dada. Aprender para nós é construir, reconstruir, constatar para mudar, o que não se faz sem abertura ao risco e à aventura do espírito. (FREIRE, 2007, p. 69).

Por isso aprender também é aprender o próprio mundo, é nas palavras de Freire, conscientização para transformar a realidade. "É preciso, portanto, fazer desta conscientização o primeiro objetivo de toda educação: antes de tudo provocar uma atitude crítica, de reflexão, que comprometa a ação". (FREIRE, 1980, p. 40). A transformação da realidade se estabelece como categoria central no pensamento de Freire em função de, além da epistemológica acima citada, sua concepção antropológica. Para Freire o homem é inconcluso, ele se faz homem na interação com o mundo e com os outros. "Por isso mesmo é que os reconhece como seres que estão sendo, como seres inacabados, inconclusos, em e com uma realidade, que sendo histórica também, é igualmente inacabada." (FREIRE, 1983, p. 83). Tendo por base tal concepção antropológica, uma das primordiais tarefas da educação é trabalhar a legitimidade do sonho ético-político da superação da realidade injusta. "É que, somente na medida em que os homens criam o seu mundo, que é mundo humano, e o criam com seu trabalho transformador - se realizam." (FREIRE, 1983, p. 169). É trabalhar a genuinidade desta luta e a possibilidade de mudar, é trabalhar contra a força da ideologia fatalista dominante, que estimula a imobilidade dos oprimidos e sua acomodação à realidade injusta, necessária ao movimento dos dominadores. (cf. FREIRE, 2000, p. 40). Os Institutos Federais de Educação, na medida em que são concebidos como política pública, possuem o compromisso social com a transformação material da realidade concreta e, isso está sendo efetivado através da oferta de uma multiplicidade de cursos e modalidades de ensino conforme explanado. 


\section{CONSIDERAÇÕES FINAIS}

O documento Instituto Federal de Educação, Ciência e Tecnologia: um novo modelo em educação profissional e tecnológica. Concepção e Diretrizes (MEC, 2010, p. 19-20) demarca a diferenciação da proposta educacional dos Institutos Federais de Educação com a que prevaleceu na educação profissional e tecnológica no Brasil por quase um século. Identifica como característica histórica o caráter funcionalista, estreito e restrito a atender os objetivos determinados pelo capital, no que diz respeito ao seu interesse por mão de obra qualificada. Em outra passagem, o mesmo documento caracteriza o modelo de educação dos Institutos Federais de Educação: “Entretanto, no momento histórico atual, as políticas para a educação profissional e tecnológica colocam-se para além do fator econômico. Daí a relevância de buscar, no caso específico, as variáveis educação e trabalho em busca de novas políticas de inclusão social, já em curso no país." (MEC, 2010, p. 33). Ou seja, o referido documento do MEC reconhece que historicamente a educação profissional e tecnológica se caracteriza como tecnicista na medida em que está voltada para atender pontualmente os interesses do sistema, mas situa a proposta dos Institutos Federais de Educação como ruptura, capaz de possibilitar independência tecnológica e desenvolvimento social.

Os Institutos Federais de Educação apresentam realmente características únicas que abrem a possibilidade de conjugarmos independência tecnológica e desenvolvimento social. A verticalização e a promoção da pesquisa aplicada possui um potencial importante para o desenvolvimento tecnológico, mas é necessário que essa verticalização realmente seja implementada com a implantação de Programas de Pós-graduação strictu sensu. Além disso, a multiplicidade no foco de atuação, o que inclui cursos técnicos integrados ao ensino médio, cursos técnicos subsequentes, PROEJA, graduações tecnológicas, bacharelados, licenciaturas, pósgraduação, cursos FIC, possibilita o atendimento de públicos diferenciados, inclusive grupos que foram historicamente excluídos do acesso à educação de qualidade. Portanto, as características dadas à proposta dos Institutos Federais de Educação apresentam um potencial que conjuga independência tecnológica com desenvolvimento social. Mas a efetivação dessas potencialidades depende dos rumos adotados no processo de implantação que está em andamento. 


\section{REFERÊNCIAS}

BRASIL. Lei no 11.892 de 29 de dezembro de 2008.

DELPHINO, Fátima Beatriz de Benedictis. A educação profissional: contraponto entre as políticas educacionais e o contexto do mundo produtivo. São Paulo: ícone, 2010.

FREIRE, Paulo. Conscientização: teoria e prática da libertação: uma introdução ao pensamento de Paulo Freire. Trad. Kátia de Mello e Silva. 3a ed. São Paulo: Editora Moraes, 1980.

Educação e Mudança. Trad. Moacir Gadotti e Lílian Lopes Martin. 3ạ ed. Rio de Janeiro: Paz e Terra, 1981.

Terra, 2007.

Pedagogia da autonomia: saberes necessários à prática educativa. 35a ed. São Paulo: Paz e

.Pedagogia da esperança: um reencontro com a pedagogia do oprimido. 6a ed. Rio de Janeiro: Paz e Terra, 1999.

2000.

Pedagogia da indignação: cartas pedagógicas e outros escritos. São Paulo: Editora UNESP,

Pedagogia do oprimido. 12a ed. Rio de Janeiro: Paz e Terra, 1983.

JURACY, Caetana. (org.). Institutos Federais Lei 11.892, de 29/12/2008. Comentários e Reflexões. Natal: IFRN, 2009.

MEC. Instituto Federal de Educação, Ciência e Tecnologia: um novo modelo em educação profissional e tecnológica. Concepção e Diretrizes. 2010. 43p.

MINAYO, Maria Cecília de Souza. Pesquisa social:teoria, método e criatividade. 28a ed. Petrópolis: Vozes, 2009.

PACHECO, Eliezer Moreira. Os Institutos Federais: uma revolução na educação profissional e tecnológica. Natal: IFRN, 2010. 